\title{
Avaliação de extratos vegetais em formulações farmacêuticas no tratamento da otite externa canina
}

\author{
[Evaluation of plant extract in dosage forms in canine otitis externa treatment]
}

\section{"Artigo Científico/Scientific Article"}

\author{
Risciela Salardi Alves de Brito ${ }^{1 *}$, Sabrina Oliveira Capella ${ }^{2}$, Jéssica Fernanda Hoffmann ${ }^{3}$, Rogerio \\ Antônio Freitag ${ }^{4}$, Fábio Raphael Pascoti Brum ${ }^{5}$, Patrícia da Silva Nascente ${ }^{2}$, Renata Costa \\ Schramm $^{5}$, Renato Vianna ${ }^{6}$, Sérgio Jorge ${ }^{7}$, Márcia de Oliveira Nobre ${ }^{7}$
}

\author{
${ }^{1}$ Programa de Pós-Graduação em Veterinária, Universidade Federal de Pelotas (UFPel), Pelotas-RS, Brasil. \\ ${ }^{2}$ Universidade Federal de Pelotas (UFPel), Pelotas-RS, Brasil. \\ ${ }^{3}$ Universidade do Vale do Rio dos Sinos (UNISINOS), São Leopoldo-RS, Brasil. \\ ${ }^{4}$ Centro de Ciências Químicas, Farmacêuticas e de Alimentos, Universidade Federal de Pelotas (UFPel), Capão do \\ Leão-RS, Brasil. \\ ${ }^{5}$ Departamento de Veterinária Preventiva, Universidade Federal de Pelotas (UFPel), Capão do Leão-RS, Brasil. \\ ${ }^{6}$ Departamento de Farmácia e Bioquímica, Unidade Católica de Pelotas (UCPel), Pelotas-RS, Brasil. \\ ${ }^{7}$ Departamento de Clínicas Veterinárias, Universidade Federal de Pelotas (UFPel), Capão do Leão-RS, Brasil. \\ *Autora para correspondência/Corresponding author: E-mail: risciela234@yahoo.com.br
}

\section{Resumo}

A otite externa é um dos problemas mais frequentes dentro da dermatologia veterinária. Os produtos comerciais comumente utilizados apresentam antimicrobianos nas formulações, que podem induzir resistência bacteriana em casos crônicos ou recidivantes. Desta forma, os produtos otológicos compostos por extratos vegetais tornam-se uma alternativa viável e com menos efeitos deletérios. O objetivo deste trabalho foi avaliar o potencial terapêutico de duas formas farmacêuticas a base de extratos vegetais das plantas urucum (Bixa orellana) e trigo (Triticum aestivum) no tratamento da otite externa canina. Extratos oleosos de urucum e trigo foram usados na formulação do composto LCFO 1001 e extratos etanólicos das mesmas plantas foram usados para o composto LCFO 1002. Foram utilizados 44 cães com sinais clínicos de otite externa, os quais foram avaliados por otoscopia e citologia. Os cães foram divididos aleatoriamente em 3 grupos LCFO $1001(n=16)$, LCFO $1002(n=14)$ e grupo controle $(n=14)$ sendo tratados uma vez ao dia durante 10 dias e reavaliados nos dias 3, 5, 7 e 10. Foi estabelecido um score de 0 a 3 de acordo com cada sinal clínico. Após 10 dias de tratamento houve redução dos sinais clínicos em todos os grupos, observou-se a equivalência dos compostos LCF0 1001 e LCFO 1002 com um produto ceruminolítico comercial. Também foi possível observar a redução no número de animais infectados por Malassezia pachydermatis e Staphylococcus pseudointermedius. Estes resultados comprovam que os compostos possuem ação na redução dos sinais clínicos da otite externa canina, assim como possuem ação antimicrobiana.

Palavras-chave: conduto auditivo; plantas medicinais; trigo; urucum.

\begin{abstract}
Otitis externa is one of the most frequent problems within veterinary dermatology. The commercial products commonly used have antimicrobials in the formulations, which can induce bacterial resistance in chronic or recurrent cases. In this way, otological products made up of plant extracts become a viable alternative with less harmful effects. The objective of this work was to evaluate the therapeutic potential of two pharmaceutical forms based on plant extracts from annatto (Bixa orellana) and wheat (Triticum aestivum) plants in the treatment of canine otitis externa. Oily extracts of annatto and wheat were used in the formulation of the compound LCFO 1001 and ethanolic extracts from the same plants were used for the compound LCFO 1002. 44 dogs with clinical signs of otitis externa were used, which were evaluated by otoscopy and cytology. The dogs were randomly divided into 3 groups LCFO 1001 ( $\mathrm{n}=16)$, LCFO 1002 $(n=14)$ and control group $(n=14)$ and treated once a day for 10 days, being reassessed on days $3,5,7$ and 10 .
\end{abstract}


A score of 0 to 3 was established according to each clinical sign. After 10 days of treatment, there was a reduction in clinical signs in all groups, the equivalence of the compounds LCF0 1001 and LCFO 1002 with a commercial ceruminolytic product was observed. It was also possible to observe a reduction in the number of animals infected by Malassezia pachydermatis and Staphylococcus pseudointermedius. These results prove that the compounds have an action in reducing the clinical signs of canine otitis externa, as well as having antimicrobial action.

Keywords: ear canal; medicinal plants; wheat; urucum.

\section{Introdução}

A otite externa canina é caracterizada como uma inflamação do conduto auditivo externo. É considerada multifatorial, sendo causada por fatores predisponentes primários e perpetuantes. Os fatores predisponentes são conhecidos por facilitar a otite externa e dentre eles estão raça e morfologia do conduto. Os fatores primários responsáveis por causar a infecção podem ser doenças alérgicas, parasitas, hipersensibilidade, corpos estranhos e doenças endócrinas. Os fatores perpetuantes são responsáveis por manter a infecção e piorar o quadro clínico do paciente com destaque para a levedura Malassezia pachydermatis e bactérias com morfologia cocos (Saridomichelakis et al., 2007; Cardoso et al., 2011).

Os principais sinais clínicos são a otalgia, prurido, eritema e aumento na quantidade de cerúmen. $\mathrm{O}$ tratamento para a otite externa inclui a limpeza auditiva e o uso de produtos tópicos com base em antibióticos, antifúngicos e antiinflamatórios (Hnilica, 2011).

Tendo em vista a abundância da flora brasileira e a eficácia de princípios ativos oriundos de plantas, a cada dia são utilizados mais produtos com extratos vegetais, buscando utilizar um tratamento com menos efeitos nocivos e prevenir a resistência microbiana em substituto aos antimicrobianos (Carvalho et al., 2007).

As plantas utilizadas neste estudo são popularmente utilizadas como laxativas, antihemorrágicas, cicatrizantes, possuindo potencial anti-inflamatório e antimicrobiano relatado (Rêgo, 1995; Galera et al., 2008). Em um estudo avaliando a cicatrização em modelo murinho, com Triticum vulgare, em diferentes concentrações foi possível observar a eficiência da mesma, acelerando o processo cicatricial (Tillmann et al., 2018). Já os estudos com o extrato oleoso de urucum em feridas abertas de animais experimentais (rato Wistar) demonstrou $\mathrm{o}$ aumento do processo cicatricial nos primeiros sete dias da cicatrização (Capella et al., 2016).

Neste contexto, o objetivo deste trabalho foi avaliar a eficiência de duas fórmulas farmacêuticas otológicas com extratos vegetais no tratamento da otite externa canina ceruminosa.

\section{Material e Métodos}

Obtenção dos Extratos Vegetais e Fitoterápicos

As amostras vegetais utilizadas para confecção dos extratos foram adquiridas comercialmente de uma empresa distribuidora de produtos naturais, com certificação de origem das sementes e ficha técnica. Para compor o produto foram produzidos extratos oleosos e etanólicos das plantas Bixa orellana e Triticum aestivum. Para obtenção dos extratos oleosos as sementes das plantas foram pulverizadas em moinho de facas, sendo utilizado o método de Soxhet com solvente extrator Hexano durante 6 horas. Após a extração, o solvente foi eliminado em rotaevaporador obtendo apenas o óleo fixo de cada planta. Para os extratos etanólicos, as sementes foram também pulverizadas em moinho de facas sendo pesadas e acondicionadas em um balão de Erlenmeyer e, adicionado Etanol PA ao balão e este levado ao ultrassom, sendo sonificado por 30 minutos. Ao final da extração os extratos de ambas as plantas foram filtrados em rotaevaparodor para retirar o solvente. Após a extração os extratos foram armazenados em frascos âmbar hermeticamente fechados e conservados $\mathrm{a}-4^{\circ} \mathrm{C}$ até sua utilização.

\section{Análise dos Compostos}

Para identificação dos compostos presentes na fração apolar dos extratos etanólico e oleoso de urucum e extrato oleoso de trigo, utilizou-se equipamento Shimadzu GC-MS QP2010 Ultra com autoinjetor AOC-20i e biblioteca de espectro de massas NIST 2011. Parâmetros de injeção, cromatografia e espectrometria de massas 
seguiram o método proposto por Lisec et al. (2006). O perfil de ácidos graxos nos extratos oleosos de trigo e urucum foi determinado por cromatografia gasosa acoplada a espectrometria de massas, seguindo o método descrito pelo Conselho Oleícola Internacional (COI, 2015). Os ésteres metílicos de ácidos graxos obtidos foram identificados por comparação com os tempos de retenção dos padrões de referência, e os resultados foram expressos como percentagem relativa de ácidos graxos. Para a análise do extrato etanólico de trigo utilizou-se cromatógrafo líquido de ultraalta eficiência (Shimadzu, Japão) acoplado a espectrômetro de massas de alta resolução do tipo quadrupolo-tempo de voo (Maxis Impact, Bruker Daltonics, Alemanha), e para as condições analíticas baseou-se em método proposto por De Vos et al. (2007).

\section{Confecção dos Produtos}

As formulações otológicas resultam de uma combinação dos mesmos tipos de extratos. A primeira com os extratos oleosos de Bixa orellana e Triticum aestivum com os aditivos óleo de amendoas doce, metilparabeno, butil hidroxi tolueno e vaselina liquida qsp (quantidade suficiente para) em fórmula base na forma líquida, sendo denominada LCFO 1001. Na segunda formulação foram utilizados os extratos etanólicos de Bixa orellana e Triticum aestivum como aditivos e metilparabeno, metabissulfito de sódio e propilenoglicol qsp em fórmula base sendo denominada LCFO 1002.

\section{Animais}

Foram incluídos neste estudo 44 cães jovens e adultos com orelhas pendulares e semipendulares, sem raça definida, de ambos os sexos com sinais clínicos de otite externa ceruminosa apresentando na citologia a presença de bactérias ou leveduras. Foram excluídos do estudo cães com histórico de otite externa recorrente, otite purulenta, otite alérgica, presença de doenças concomitantes, fêmeas prenhes, otite externa de origem parasitária, cães com estenose de conduto e com presença de massas nodulares no conduto auditivo externo.

Os cães foram divididos em três grupos de forma aleatória conforme o tratamento, sendo considerados dois grupos teste e um grupo controle positivo. Neste estudo, todos os animais diagnosticados receberam tratamento. $\mathrm{O}$ grupo LCFO-1001 $(\mathrm{n}=16)$ foi tratado com o composto
LCFO-1001(extratos oleosos de urucum e trigo e aditivos), grupo LCFO-1002 ( $\mathrm{n}=14)$ recebeu tratamento com LCFO-1002 (extratos etanólicos de urucum e trigo e aditivos) e o grupo controle positivo $(n=14)$ recebeu o tratamento com um ceruminolítico comercial composto por ácido salicílico $0,11 \mathrm{~g}$, ácido lático $2,98 \mathrm{~g}$, essência herbal $0,01 \mathrm{~g}$ e veículo, optou-se a utilização de um ceruminolítico comercial devido ao padrão de otite ceruminosa escolhido para o estudo. Os animais foram tratados uma vez a cada 24 horas durante 10 dias consecutivos. Para o tratamento, o conduto auditivo foi previamente limpo com o próprio produto com auxílio de gaze, após foram aplicadas quatro gotas para cães com menos de $15 \mathrm{~kg}$ e oito gotas para cães com mais de $15 \mathrm{~kg}$.

\section{Avaliações Clínicas}

Os animais foram avaliados antes do tratamento (D0), no terceiro (D3), quinto (D5), sétimo (D7) e décimo (D10) dia de tratamento. Foi realizada a inspeção e palpação do conduto auditivo e os sinais clínicos de otalgia e prurido os quais foram classificados como ausente (0) leve (1) moderado (2) intenso (3) e o reflexo otopodal foi classificado como ausente (0) presente (1). Foi realizada a otoscopia, sendo analisados os sinais clínicos de eritema classificado em ausente (0), leve (1), moderado (2) e intenso (3). A quantidade de cerúmen foi avaliada como leve (0), moderado (1) e grave (2). Pela avaliação foi possível realizar um somatório por animal e por grupo durante cada dia de avaliação. Após a otoscopia foi aferida a temperatura auditiva com termômetro Geratherm Rapid ${ }^{\circledR}$ e coletadas amostras para micologia e bacteriologia.

\section{Avaliação da Ação Antimicrobiana}

As amostras dos 44 cães foram coletadas, antes do início do tratamento (D0) e ao final do tratamento (D10), as coletas foram realizadas com auxílio de swab estéril introduzido no conduto auditivo externo. Para cultura bacteriana foram semeadas em placas de Petri contendo ágar sangue ovino $5 \%$ e ágar MacConkey e incubadas em estufa bacteriológica a uma temperatura de $37^{\circ} \mathrm{C}$ durante 48 horas. $\mathrm{O}$ crescimento bacteriano foi submetido a provas de catalase e coloração de Gram, conforme a observação procederam testes de oxidase, coagulase e caracterização bioquímica com provas de fermentação de carboidratos. Para o isolamento fúngico, as amostras foram cultivadas em ágar Saboraud acrescidas de 
cloranfenicol, e mantidas em estufa microbiológica a uma temperatura de $37^{\circ} \mathrm{C}$ durante 48 horas e, posteriormente, foi realizada a citologia das colônias que apresentaram crescimento.

\section{Análise Estatística}

Foi utilizado o pacote estatístico SPSS ${ }^{\circledR}$ 20.0, considerando um nível mínimo de significância de $95 \%$. Todos os grupos foram comparados entre si utilizando o teste de KruskalWallis. Para a análise entre os dias de coleta foi utilizado o teste de Friedman. Já para a avaliação da temperatura auditiva entre os grupos e entre os dias de coleta foi utilizado o cálculo de ANOVA com medidas repetidas ao longo do tempo, para citologia foi utilizado teste de Tukey e para a análise da redução dos microrganismos foi utilizado o teste de McNermar.

\section{Resultados e Discussão}

Os resultados demonstraram que os dois grupos testes LCFO-1001 e LCFO-1002 foram similares ao grupo Controle Positivo já que ambos responderam da mesma forma durante o tratamento, não havendo diferença estatística em relação aos sinais clínicos apresentados. Em todos os grupos o somatório dos sinais clínicos foi diminuindo ao decorrer do tratamento, demonstrando diferenças estatísticas (Figura 1).

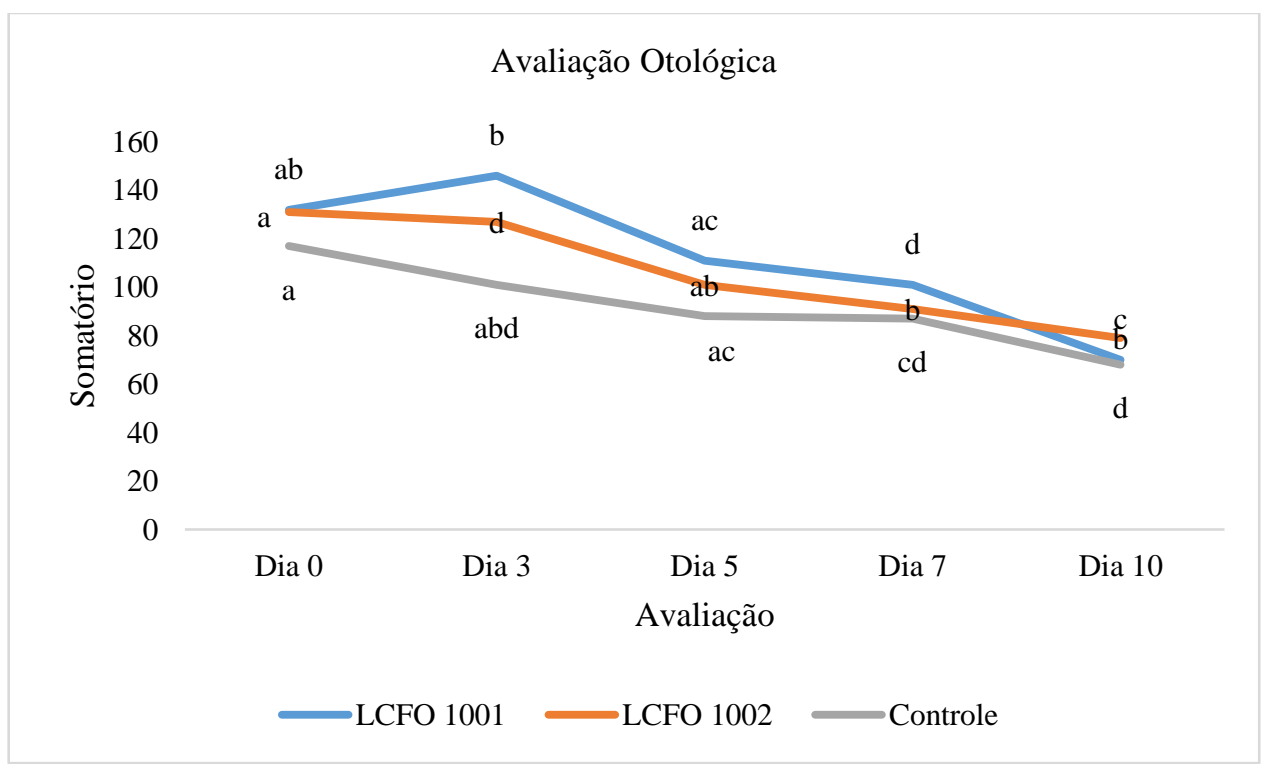

Figura 1. Demonstração do somatório e diferenças estatísticas das análises clínicas realizadas durante o tratamento da otite externa em cães tratados com os compostos LCF0-1001, LCFO- 1002 e controle positivo. Letras diferentes indicam diferença estatística no teste de Friedman $(p<0,05)$ e as letras iguais não diferem estatisticamente.

O grupo LCFO-1001 apresentou aumento no somatório dos sinais clínicos no momento D3, que posteriormente reduziu como os demais grupos. Este aumento foi determinado principalmente pela manifestação de otalgia nos cães tratados. Os demais sinais clínicos avaliados isoladamente, produção de cerúmen, eritema, prurido e reflexo otopodal não demonstraram diferenças estatísticas entre os tratamentos e todos diminuíram progressivamente. $\mathrm{O}$ desenvolvimento da otalgia pode ser atribuído a ação próinflamatória dos extratos de urucum e trigo, sendo os extratos oleosos apresentam uma intensificação da resposta. Este efeito estimula a migração de células polimorfonucleares para o local da lesão e intensifica a migração de fibroblastos $\mathrm{e}$ neovascularização, o que pode inicialmente aumentar os sinais de inflamação e após diminuir com a resposta do organismo. Este efeito é importante para a redução da taxa bacteriana sem o uso de antibacterianos, já que o organismo combate a infecção por meio de mecanismos da resposta imune (Santos et al., 2014). Da mesma forma a ação pró-inflamatória foi demonstrada nos primeiros dias de tratamento de feridas abertas com óleo de urucum. $\mathrm{O}$ maior recrutamento de células pode ocorrer devido ao efeito quimiotático dos ácidos linoleico e oleico que presentes no extrato oleoso de urucum, os quais aceleram a retração de feridas nos primeiros dias de tratamento (Capella et al., 2016).

A temperatura auditiva apresentou uma média entre os dias de coleta para o grupo LCFO1001 de $37,4^{\circ} \mathrm{C}$, para o grupo LCFO-1002 de $37,5^{\circ} \mathrm{C}$ e para o grupo controle positivo de 37 , $6^{\circ} \mathrm{C}$, não apresentando diferença estatística entre 
os diferentes grupos $(\mathrm{p}=0,336)$. Embora entre as coletas tenham sido observada diferença estatística $(\mathrm{p}=0,008)$ na quarta avaliação (D7) com temperatura mais elevada diferindo dos demais dias de avaliação. Não foi encontrada interação entre os grupos e as coletas $(\mathrm{p}=0,186)$, portanto a temperatura não foi modificada de acordo com o tratamento utilizado. A temperatura auditiva encontrada neste estudo foi menor do que a considerada normal do conduto auditivo de cães que varia entre $38,2^{\circ} \mathrm{C}$ e $38,5^{\circ} \mathrm{C}$ (Harvey e Paterson, 2014). A temperatura e a umidade do conduto fazem parte o microclima auditivo, alguns estudos relacionam o aumento com o favorecimento do crescimento microbiano (Harvey e Paterson, 2014), outros consideram que a temperatura e umidade dentro do conduto auditivo são muito estáveis não sofrendo alteração em cães com otite externa (Yoshida et al., 2002).

Dentre os microrganismos foram isolados em maior quantidade Malassezia pachydermatis $(64,13 \%)$, Sthaphylococcus pseudointermedius $(47,91 \%)$, Sthaphylococcus coagulase negativa (5,20\%), Sthaphylococcus aureus (3,13\%), Proteus spp e Pseudomonas spp. (1,04\%). Destes microrganismos isolados, apenas apresentaram redução durante o tratamento a levedura $M$. pachydermatis e a bactéria $S$. pseudointermedius. Malassezia pachydermatis apresentou 68,75\% de crescimento para o grupo LCFO-1001 no dia 0 , já no dia 10 aumentou para 93,75\% ( $\mathrm{p}=0,031)$, para o grupo LCFO-1002 apresentou crescimento em $61,11 \%$ reduzindo para $19,44 \%$ no dia 10 $(\mathrm{p}=0,001)$, no grupo Controle Positivo apresentou $62,50 \%$ de crescimento reduzindo para $4,16 \%$ no dia $10 \quad(\mathrm{p}=0,00)$. Para a bactéria $S$. pseudointermedius, o grupo LCFO-1001 apresentou $62,5 \%$ de crescimento reduzindo para $46,82 \%$ no dia 10 ( $\mathrm{p}=0,08$ ), no grupo LCFO- 1002 foi encontrado $50 \%$ de crescimento reduzindo para $13,88 \%$ na última avaliação $(\mathrm{p}=0,031)$, o grupo Controle Positivo apresentou $25 \%$ de crescimento no dia 0 mantendo em $25 \%$ no dia 10 , não houve diferença estatística $(\mathrm{p}=0,125)$ (Tabela 1). Estudo com otite externa canina, também avaliando a eficiência do Triticum aestivum frente a otite externa, demonstrou que após 14 dias de tratamento os cães apresentaram redução dos microrganismos isolados e melhora nos sinais clínicos, demonstrando o poder antimicrobiano e antiinflamatório do extrato (Fernandes et al., 2017). A quantidade de leveduras $M$. pachydermatis aumentou apenas no grupo LCFO1001, o qual apresenta em sua constituição extratos oleosos, este aumento no crescimento, possivelmente, ocorreu devido a $M$. pachydermatis ser uma levedura lipofílica, embora não seja lipodependente, a presença do óleo serve como fator nutricional, potencializando o seu crescimento (Carfachia et al., 2011).

Tabela 1. Avaliação do crescimento da Malassezia pachydermatis e Staphylococcus pseudointermedius em cultura microbiológica de 44 amostras obtidas de cães com otite externa antes e após os tratamentos.

\begin{tabular}{|c|c|c|c|c|c|c|}
\hline Microorganismo & & Dia 0 & & & Dia 10 & \\
\hline & LCFO 1001 & LCFO 1002 & Controle & LCFO 1001 & LCFO 1002 & Controle \\
\hline $\begin{array}{l}\text { Malasssezia } \\
\text { pachydermatis }\end{array}$ & $68,75 \%$ & $61,11 \%$ & $62,50 \%$ & $93,75 \%$ & $19,44 \%$ & $4,16 \%$ \\
\hline $\begin{array}{l}\text { Staphylococcus } \\
\text { pseudointermedius }\end{array}$ & $62,5 \%$ & $50 \%$ & $25 \%$ & $46,82 \%$ & $13,88 \%$ & $25 \%$ \\
\hline
\end{tabular}

O potencial antimicrobiano de extratos compostos pelas plantas que compõe os produtos utilizados já foi referenciado por alguns autores frente a Staphylococcus aureus, Vibrio cholarae, Bacillus subtilis, Bacillus cereus, Lactobacillus plantarum, Klebsiella pneumoniae, Salmonella typhi, Streptococcus mutans, Streptococcus sanguinis e Proteus vulgaris (Abayomi et al., 2014, Ciro et al., 2014; Natividad e Rafael, 2014; Rajoria, et al., 2015; Alim et al., 2016). A redução bacteriana pode também ter relação com a limpeza do conduto auditivo, a qual reduz os debris celulares e auxilia no reestabelecimento do microclima auditivo reduzindo o substrato para crescimento microbiano (Mueller et al., 2013), desta maneira a atividade microbiana dos extratos pode ter tido uma ação conjunta com a atividade ceruminolítica dos mesmos a qual diminui a disposição de nutrientes para o crescimento microbiano.

$\mathrm{Na}$ avaliação cromatográfica o extrato oleoso de trigo apresentou a seguinte composição majoritária: ácido palmítico, ácido linoleico, ácido oleico, 2-3-dihidroxipropil, adipostatina A, 
estigmastanol, clionasterol e resorcina. Os ácidos graxos mais abundantemente encontrados foram: ácido pedroselínico, ácido pentadecanóico, ácido palmitoleico, ácido linoleico, ácido alfalinolênico, ácido oleico, ácido esteárico, ácido gondoico, ácido ecosanoico, ácido heneicosílico. Já no extrato oleoso de urucum foram encontrados os compostos majoritários Tetrapenol, espatulenol, alfa-guaiene, beta-Cubebene e Selina6-en-4-ol. Sendo encontrado o perfil de ácidos graxos com maior abundância: ácido hexadecanóico, ácido 9-hexadecanóico, ácido petroselínico, ácido pentadecanóico, ácido palmitoleico, ácido palmítico, ácido linoleico, ácido oleico, ácido elaídico, ácido esteárico.

Para o extrato etanólico de urucum os compostos majoritários foram cicloexeno, alfacopaene, alfa-guaiene, naphtalene, selina-6-em-4ol, espatulenol, decahydro-1,1,7-tr, 1-HCycloprop[e]azulen-7-ol, thunbergol, ácido palmitico, ácido hexadecanoico, ácido linoleico, hexadeca-2,6,10,14,18,22- tetracosahexae, esqualeno, 2,6,10,14-Hexadecatetraen-1ol,37,11,15-tetr, trilinolein. Já os ácidos graxos prevalentes encontrados foram ácido cáprico, ácido cis-2-decenóico, ácido 2-Hexadecanóico, ácido petroselínico, ácido pentadecanóico, ácido palmitoleico, ácido palmítico, ácido linoleico, ácido alfa-linolênico, ácido oleico, ácido elaídico, ácido esteárico, ácido gondoico, ácido eicosanóico e ácido heneicosanóico. Já para o extrato etanólico de trigo foram encontrados os compostos 9,12,13trihidroxi-10,15-octadecadienóico, ácido maléico, ácido pinélico, 5-5'- Ácido desidrodiferúlico e os compostos fenólicos ácido 4-Hidroxibenzeico, ácido caféico, catequina, ácido ferrúlico, ácido pcumárico, ácido sinápico, ácido sirínico, ácido vanílico e ácido salicílico.

Enquanto o extrato de urucum provoca a migração celular para a defesa local, os extratos de trigo estimulam a multiplicação dos fibroblastos e a produção de tecido cicatricial. Triticum aestivum também apresenta potencial no processo cicatricial, principalmente devido à presença de fitoestimulinas que agem sobre fibroblastos, os quais estimulam a capacidade de sintetizar fibras colágenas e glicosaminoglicana. Um estudo utilizando a evolução da cicatrização de feridas em animais experimentais contendo diferentes concentrações de Triticum spp. demonstrou eficiência na cicatrização de feridas in vivo (Tillmann et al., 2018) outro estudo no tratamento de feridas em coelhos também demonstrou a eficiência na cicatrização principalmente devido à estimulação da força tensiométrica (Tillmann et al., 2014).

Os resultados sugeriram que os produtos possuem potencial no tratamento da otite externa canina, porém precisam de adaptações na sua composição para aumentar a eficácia não exacerbando a resposta inflamatória nos dias iniciais de modo que estimule a migração de células inicialmente, mas permita a redução da resposta inflamatória dos dias seguintes, além disso, busca-se aumentar a atividade antimicrobiana, visto que reduziu significativamente somente para isolados de $M$. pachydermatis e $S$. pseudointermedius.

\section{Conclusão}

As fórmulas otológicas LCFO 1001 composta pelos extratos oleosos (urucum e trigo) e LCFO 1002 extratos etanólicos (urucum e trigo) foram capazes de reduzir os sinais clínicos de otite externa com eficiência similar a um produto ceruminolítico comercial amplamente utilizado, porém o LCF0 1002 foi considerado melhor, pois obteve ação mais potente frente a leveduras $M$. pachydermatis e não provocou otalgia.

\section{Conflito de Interesse}

Os autores do trabalho declaram que esse estudo não apresenta nenhum conflito de interesse.

\section{Comitê de Ética}

O presente estudo foi avaliado e aprovado pela Comissão de Ética em Experimentação Animal CEEA No 9055/UFPel da Universidade Federal de Pelotas.

\section{Agradecimentos}

Ao $\mathrm{CNPq}$ pelo financiamento de bolsa de produtividade científica (processo 19 3106619/2016-5) e aos laboratórios de Microbiologia e Parasitologia do Instituto de Biologia da UFPel e ao Laboratório de Bacteriologia Veterinária- UFPel.

\section{Referências}

Abayomi, M.; Adebayo, A.S.; Bennett, D.; Porter, R.; Campbell, J.S.; Dawkin, G. Phytochemical testing and in vitro antibacterial activity of Bixa orellana (annatto) seed extract. British Journal of Pharmaceutical Research, 4(11): 1387-1399, 2014. 
Alim, S.; Bairagi, N.; Shahriyar, S.; Kabir, M.; Rahman, M.H. In vitro antibacterial potential of Bixa orellana $L$. against some pathogenic bacteria and comparative investigation on some standard antibiotics. Journal of Pharmacognosy and Phytochemistry, 5(2): 178-181, 2016.

Cafarchia, C.; Figueiredo, L.; Latta, R.; Montagna, M.; Otranto, D. In vitro antifungal susceptibility of Malassezia pachydermatis from dogs with and without skin lesions. Veterinary Microbiology, 155 (2-4): 395-398, 2011.

Capella, S.; Tillmann, A.; Félix, A.; Fontoura, E.; Fernandes, C.; Freitag, R.; Santos, M.; Félix, S.; Nobre, M. Potencial cicatricial da Bixa orellana L. em feridas cutâneas: estudo em modelo experimental. Arquivo Brasileiro de Medicina Veterinária e Zootecnia, 68 (1): 104-112, 2016.

Cardoso, J.; Machado, L.; Melussi, M.; Zamarian, T.; Carnielli, C.; Júnior, J. Dermatopatias em cães: Revisão de 257 casos. Archives of Veterinary Science, 16 (2): 66-74, 2011.

Ciro, G.L.; Zapata, J.E.; Lopez, J. In vitro evaluation of Bixa orellana L. (annatto) seeds as potential natural food preservative. Journal of Medicinal Plant Research, 8(21): 772-779, 2014.

COI. Conselho Oleícola Internacional. Normas para comércio padrão aplicado aos azeites e óleos de bagaço de azeitona COI/T.15/NC n ${ }^{\circ}$ 3/Rev. 8 . Disponível em: <https://www.internationaloliveoil.org/>. Acesso em: 02 set. 2019.

De Vos, R.; Moco, S.; Lommen, A.; Keurentjes, J.; Bino, R.; Hall, R. Untargeted large-scale plant metabolomics using liquid chromatography coupled to mass spectrometry. Nature Protocols, 2 (4): 778-791, 2007.

Fernandes, C.P.M.; Hijano, A.; Lima, C.S.; Fontoura, E.G.; Schramm, R.C.; Félix, S.; Nobre, M. Ensaio clínico, randomizado, duplo cego, para tratamento experimental de otite externa com extrato aquoso de Triticum aestivum. Pesquisa Veterinária Brasileira, 37(11): 1270-1274, 2017.

Galera, P.D.; Falcão, M.S.; Ribeiro, C.R.; Valle, A.C.V.; Laus, J.L. Utilization of the aqueous extract of Triticum vulgare (bandvet ${ }^{\circledR}$ ) after superficial keratectomy in domestic cats afflicted with corneal sequestrum. Ciência Animal Brasileira, 9(3): 714-720, 2008.
Harvey, G.R.; Paterson, S. Otitis externa - an essential guide to diagnosis and treatment. $1^{\text {st }}$ ed. New York: CRC Press, 2014. v.1, 168p.

Hnilica, K.A. Doenças dos olhos das garras, dos sacos anais e dos canais auditivos. In: Dermatologia de pequenos animais: atlas colorido e guia terapêutico. Elsevier, 2011. p.395.

Lisec, J.; Schauer, N.; Kopka, J.; Willmitzer, L.; Fernie, A.R. Gas chromatography mass spectrometry-based metabolite profiling in plants. Nature Protocols, 1(1): 387-396, 2006.

Mueller, E.N.; Guiot, E.G.; Santin, R.; Meireles, M.C.A.; Schuch, L.F.D.; Nobre, M.O. Efeito auxiliar do ceruminolítico na terapia tópica de cães (Canis lupus familiaris) com otite externa ceruminosa. Ciência Animal Brasileira, 14(1): 59-64, 2013.

Natividad, L.R.; Rafael, R.R. Carotenoid analyses and antibacterial assay of annatto (Bixa oerellana L.), carrot (Daucus carota L.), corn (Zea mays L.) and tomato (Solanum lycopersicum L) extracts. Research Journal of Recent Sciences. 3(3): 40-45, 2014.

Rajoria, A.; Mehta, A.; Mehta, P.; Ahirwal, L.; Shukla, S. Phytochemical analysis and estimation of major bioactive compounds from Triticum aestivum L. grass with antimicrobial potential. Pakistan Journal of Pharmaceutical Sciences, 28(6): 2221-2225, 2015.

Rêgo, T.J.A. Fitogeografia das plantas medicinais no Maranhão. $2^{\mathrm{a}} \mathrm{ed}$. vol. 2, São Luís: UFMA, 1995. p.149.

Santos, J.A.A.; Sousa, M.F.A.M.; Silva, E.L.V.; Aguiar Júnior, F.C.A. Avaliação histomorfométrica do efeito do extrato aquoso de urucum (norbixina) no processo de cicatrização de feridas cutâneas em ratos. Revista Brasileira de Plantas Medicinais, 16(93): 637-643, 2014.

Saridomichelakis, M.N.; Farmaki, R.; Leontides, L.S.; Koutinas, A.F. Aetiology of canine otitis externa: a retrospective study of 100 cases. Veterinary Dermatology, 18(5); 341-347, 2007.

Tillmann, M.T.; Felix, A.O.C.; Mueller, E.N.; Felix, S.R.; Alves, G.H.; Ramos, T.S.; Freitag, R.A.; Fernandes, C.G.; Nobre, M.O. Use of Triticum aestivum in open wound healing: a clinical, pathological, and tensiometric assessment in the rabbit model. Arquivo 
Brasileiro de Medicina Veterinária e Zootecnia, 66(6): 1757-1761, 2014.

Tillmann, M.T.; Mendes, C.B.M.; Fischer, G.; Júnior, A.S.V.; Fernandes, C.G.; Nobre, M.O. Triticum aestivum in open skin wounds: cytotoxicity and collagen histopathology.
Semina: Ciências Agrárias, 39 (4): 15471554, 2018.

Yoshida, N.; Naioto, F.; Fukata, T. Studies of certain factors affecting the microenvironment and microflora of the external ear of the dog in health and disease. Journal of Veterinary Medical Science, 64(12): 1145-1147, 2002. 